Nevşehir Bilim ve Teknoloji Dergisi Cilt 6(ICOCEE 2017 Özel Sayı) 388-396 2017

DOI: 10.17100/nevbiltek.322169

URL: http://dx.doi.org/10.17100/nevbiltek.322169

\title{
Tekstil Endüstrisi Atıksularının Arıtımında Kullanılan Proseslerin Araştırılması
}

\author{
Osman Önder NAMAL * \\ Nevşehir Hacı Bektaş Veli Üniversitesi, Mühendislik-Mimarlık Fakültesi, Çevre Mühendisliği Bölümü,
}

Nevşehir

$\ddot{O} z$

Çevreyi ve insanları tehdit eden en önemli tehlikeli atıklardan biride tekstil endüstrisi atıksularıdır. Renkli tekstil endüstrisi atıksuları su ortamlarında birikerek suyun estetik görünümünü bozarlar ve sşık penetrasyonunu azaltırlar. Işık penetrasyonunun ve çözünmüş oksijenin azalması canlıların tükenmesine neden olur ve su kaynaklarının kullanımını kısıtlar. Ayrıca bazı boyaların toksik bileşikler içerdiği de bilinmektedir. Çok küçük miktarlarda bile renkli tekstil atıksuları yüksek dispersiyon oranına sahip olduğu için geniş su kütlelerine yayılabilmektedir. Renkli tekstil atılsuları arıtılmadan deşarj edildiğinde çevreyi tehdit etmektedir. Renk giderimi için adsorpsiyon, filtrasyon ve kimyasal prosesler tercih edilirken, renkli atıksulardan KOI gideriminde biyolojik aktif çamur sistemleri kullanılmaktadır. Simdilerde nanotekstil karakterli membran prosesler daha etkili arıtım için kullanılmaya başlanmıștır. Arıtma alternatifleri birbiriyle kıyaslandığında diğer ileri oksidasyon tekniklerine nazaran Fenton proseslerin tekstil atıksularından renk ve KOI giderimine daha uygun olduğu sonucuna varılabilir. Atıksu arıtımında geniş bir uygulama alanı bulan membran prosesler konsantre atık deşarj eden endüstrilerin ekonomisine büyük bir katkı sağlayabilmektedir. Dahası, Membran prosesler kirletici yükünü büyük oranda azaltabilmektedir. Araştırmalara göre tekstil atıksuyunun arıtımında ters ozmoz ve nanofiltrasyon membranları başarıyla kullanılabilmektedir. Nanofiltrasyon membranlarının tıkanma problemlerinin oldukça düşük seviyelerde olduğu ve renk giderim veriminin \%95 gibi oldukça yüksek seviyelere ulaşabildiği görülmektedir.

Anahtar Kelimeler: Arıtma teknolojileri, renkli atıksular, tekstil endüstrisi.

\section{Investigation of Processes Used in the Treatment of Textile Industry Wastewaters}

\begin{abstract}
One of the most important harmful wastes threatening people and nature is textile industry wastewaters. Colored textile wastewaters accumulating in water bodies disrupts the aesthetic appearance of water and reduces light penetration to water. Reduction of light penetration and dissolved oxygen causes the extinction of living and limits the using of water sources. It is also known that some dyes contains the toxical substances. Even in very small quantities, colored textile wastewaters can spread to large water bodies since it has high dispersion ratio. Colored textile wastewaters threatens to environment when it was discharged without treatment. While adsorption, filtration and chemical processes is preferred for color removal, biological activated sludge systems are used the COD removal from colored wastewaters. Nowadays, membrane processes having the character of nanotech textile has been started to use for more effective treatment. When treatment alternatives compared with each other, it was concluded that the Fenton processes more appropriate for COD and color removal from textile wastewaters in comparison with other advanced oxidation techniques. Membrane processes that find a wide application area in wastewater treatment can make a great contribution to economy of industries discharging concentrated waste. Moreover, membrane processes can reduce the pollution load to great extent. According to researches, it is determined that the reverse osmosis and nanofiltration membranes can be used successfully in treatment of textile wastewaters. It is seen that clogging of nanofiltration membranes is very low levels and efficiency of color removal can reach to very high values such as $95 \%$.
\end{abstract}

Keywords: Treatment technologies, colored wastewaters, textile industry.

*e-mail: osmannamal@nevsehir.edu.tr 


\section{Giriş}

Tekstil endüstrisinden kaynaklanan atıksular yüksek konsantrasyonlarda boya, BOİ, KOİ ve askıda katı madde içerirler. Yüksek oranda KOİ ve renk içeren maddeler atıksuyu estetik açıdan bozulmasına neden olarak normal hayat için gerekli olan çözünmüşs oksijen miktarını azaltır ve atıksuyun arıtımını daha zor bir hale getirir [1]. Boyama işlemi açısından bakıldığında oluşan atıksuyun özellikleri prosesin kimyasına, boyama işleminin sürekli veya kesikli oluşuna göre değişmektedir [2]. Alıcı su ortamlarına deşarj edilen ve renk içeren atıksular ışığın su ortamına nüfus etmesine engel olur ve buna bağlı olarak fotosentez faaliyetleri olumsuz etkilenir. Ayrıca boyar maddeler bazı sucul organizmalarda birikir ve bu durum toksik ve kanserojenik ürünlerin meydana gelme riskini de beraberinde getirmektedir [3]. Bu toksik etkiler alıcı su ortamlarındaki mevcut ortamın flora ve faunasının değişmesine neden olmaktadırlar. Boyar madde içeren atık suların arıtılmadan doğrudan alıcı ortama verilmesi sonucunda anaerobik şartlar altında toksik ve karsinojenik özelliklere sahip olan aromatik aminlerin oluşması gibi önemli bir çevresel etkiye sebep olabilmektedir [4]. Bu bağlamda tekstil endüstrilerinden kaynaklanan ve yüksek miktarda boyar madde içeren atıksuların arıtılmasında renk giderim prosesleri ekolojik açıdan önem kazanmaktadır [3]. Tekstil endüstrisi atıksularında mevcut bulunan kirletici parametrelerinin geniş bir aralıkta yer alması, bu sektöre ait atıksuların arıtılmasında farklı arıtma yöntemlerinin kullanılmasını gerekli kılmaktadır [1]. Bu yüzden tekstil atıksuları alıcı ortamlara deşarj edilmeden önce kirletici parametrelerin kaynakları belirlendikten sonra atıksuyun karakteristiğine uygun olarak gerekli arıtma işlemlerinin uygulanması gerekmektedir. Bu çalışmada tekstil atıksularının arııımında yaygın olarak kullanılan arıtma prosesleri, bu proseslerin sağladığı avantaj ve dezavantajlar ile proses seçiminde göz önünde bulundurulması gereken hususlar araştırılmıştır.

\section{Tekstil Endüstrisi Atıksularının Arıtımında Kullanılan Yöntemler}

Atıksulardan renk gideriminde yaygın olarak kullanılan prosesler dört sınıfa ayrılabilir. Bunlar: (i) kolagülasyon-flokülasyon, iyon değişimi, adsorpsiyon ve membran filtrasyon gibi fiziksel ve fizikokimyasal yöntemler, (ii) kimyasal oksidasyon yöntemleri, (iii) aerobik ya da anaerobik parçalanma gibi biyolojik yöntemler, (iv) elektrodiyaliz gibi elektrokimyasal yöntemler olarak sıralanabilir [5].

\subsection{Fiziksel ve Fizikokimyasal Yöntemler}

Boya içeren atıksuların koagülant maddelerle arıtımı renk giderimi için oldukça bilinen bir metottur [6]. Kimyasal çöktürme yöntemiyle tekstil atıksularının arıtılması işleminde hızlı karıştırma, yumaklaştırma ve çöktürme aşamaları uygulanır [7]. Proses; aliminyum, kalsiyum ya da ferrik iyonları gibi maddelerin boya içeren atıksulara ilavesini içerir [6]. Boyarmaddeler çöktürme işlemi esnasında flokların yüzeyine tutunarak veya metal hidroksitlere bağlanarak çöktürülmek suretiyle giderilirler [2]. Çöktürme işleminin verimi büyük oranda çökeltme verimine bağlı olduğundan, yumaklaştırma yardımcısı olarak polielektrolit uygulaması yaygındır [7]. Bu proses dispers ve kükürt boyar maddelerinin istenen şekilde gideriminde ekonomik olarak ucuzdur ancak kimyasalların maliyeti sebebi ile bazen pahalı olabilmektedir. Bununla birlikte bu prosesin dezavantajı son ürün olarak büyük miktarlarda konsantre çamur oluşması ve prosesin pH'a bağımlılık göstermesidir [6]. Bununla birlikte, reaktif boyaların ve bazı 
asidik boyaların flokülasyon ile gideriminde ancak \% 20 arıtım verimi sağlanabildiği için yeterli renk giderimi elde edilememektedir [7].

Boyaların çoğu kimyasal olarak ya anyonik ya da katyonik olduğu için, teorik olarak iyon değiştirici reçinelerle giderilebilirler [5]. Atıksular mevcut bölgeler doygunluğa ulaşıncaya kadar iyon değiştirici reçinelerden geçer. Bu yolla hem boya katyonları hem de boya anyonları giderilebilmektedir. $\mathrm{Bu}$ yöntemin avantajı rejenerasyonda adsorbent kaybının yaşanmaması ve çözünebilen boyaların giderilerek solventlerin kullanıldıktan sonra geri kazanılabilmesidir [8]. Bununla birlikte iyon değiştirici reçineler diperse boyalar gibi geniş bir boya aralığında kullanımı kısıtlı olduğu için ve doygunluğa ulaşıldığında pahalı organik organik solventlerle rejenerasyon zorunlu olduğu için boya içeren atıksuların arıtımında geniş ölçüde kullanılmamaktadır. Bu proses rejenerasyon aşamasında sonradan geri kazanılabilen metanol gibi organik solventler kullanılırsa ekonomik olmaktadır [5].

Adsorpsiyon prosesi atıksulardan renk giderimi sağlamak açısından oldukça etkili bir metottur. Biyolojik olarak parçalanması zor veya imkânsız organik boyar maddeler uygun adsorbanların yüzeyinde tutularak atıksudan giderilebilirler [2]. Renk gideriminde adsorpsiyon metodunun temel esası çeşitli boyaların adsorbana olan afinitesine dayanır. Boya-adsorban arasındaki etkileşimler; adsorbanın yüzey alanı, partikül boyutu, sıcaklık, pH değeri ve temas süresi gibi birtakım fiziksel ve kimyasal faktörlerden etkilenmektedir [11].Adsorpsiyon prosesinde kullanılan ve en etkin adsorban maddelerden bir tanesi aktif karbondur. Aktif karbon adsorpsiyonu, atıksulardan renk gideriminde en yüksek verim sağlayan işlemlerden biridir [7]. Ancak bazı asit ve reaktif boyalar yüksek çözünürlüğe sahip olduklarından dolayı adsorpsiyon yöntemi ile atıksulardan giderilmeleri zordur [2]. Bununla birlikte aktif karbon büyük bir yüzey alanına sahip olmasından dolayı birçok adsorbente nazaran yüksek adsorpsiyon kapasitesine olsa da, 2 nm'den daha küçük mikropor yapısına sahip olduğu için büyük ölçüde boya içeren atık suların arıtımında etkili değildir [4]. Ayrıca aktif karbon pahalıdır ve rejenerasyonda karşılaşılan zorluklar aktif karbonun renk giderimindeki kullanımını kısıtlamaktadır [9]. Adsorpsiyon prosesinde karşılaşılan diğer olumsuzluklar bakım maliyetlerinin yüksek olması ve atıksuyun adsorpsiyon kolonlarına verilmeden önce askıda katı madde içeriğinin düşürülmesi gerekliliğgi olarak sıralanabilir [10]. Aktif karbon adsorpisoyunu ile renk giderimi katyonik, mordant ve asit boyalar için etkiliyken, dispers, direkt, vat, pigment ve reaktif boyalar için elde edilen giderim verimleri daha düşüktür. Sonuç olarak adsorpsiyon kapasitesinin kullanılan aktif karbona ve atık suyun tipine göre değiş̧iklik değiş̧iklik gösterdiği söylenebilir [4].

Membran filtrasyonu ile atık sulardan renk giderimi sağlamak mümkündür [4]. Membran prosesler ayrıca boyama işleminde kullanılan birtakım boyaların, yardımcı kimyasalların ve suyun geri kazanılması amacıyla kullanılabilmektedir [2]. Oluşan konsantre akım ise kirletici konsantrasyonuna bağlı olarak ileri arıtmaya tabi tutulmakta ya da alıcı ortama deşarj edilmektedir. Membran proseslerle boyar madde giderilmesi için uygun teknolojinin seçimi, boyanın türüne ve istenilen çıkış suyu kalitesine göre değişiklik göstermektedir [2, 11]. Membran teknolojisinin temel dezevantajları oldukça pahalı olması, sık membran kirlenmesine sebep olması, ön arıtma gerektirmesi ve çevreye deşarj edilmeden önce arıtılması gereken konsantre bir akım oluşturması olarak sıralanabilir [10, 11]. Ön arıtma membran filtrasyon için uygun askıda katı madde giderimi sağlayarak, membranın ömrünü uzatır [11]. Son zamanlarda tekstil atıksularından etkili bir renk giderimi için membran fltrasyonu ile birlikte ozonlama 
kombine bir şekilde uygulanmaktadır [12]. Membran filtrasyonunda en çok bilinen uygulamalar ultrafiltrasyon, nanofiltrasyon, mikrofiltrasyon ve ters ozmoz olarak siralanabilir [5].

Ters ozmoz, genellikle tekstil atıksularında bulunan iyonların ve büyük maddelerin ayrıştırılarak giderilmesi amacıyla kullanılmaktadır. Bu prosesle asitlerin, metal komplekslerinin ve oldukça yüksek çözünürlüğe sahip olan bazik bazik boyaların atıksudan tamamen ayrılması mümkün olabilmektedir. Direkt ve reaktif boyama işlemlerinde yüksek konsantrasyonlarda elektrolit kullanıldığı için bu tür boyama işlemleri sonucunda oluşan atıksulara ters ozmoz işlemi uygulanamamakta ve ancak yıkama sularına uygulanabilmektedir [2]. Ters osmoz membranları ile \%90'nın üzerinde arıtma verimi sağlanabilse de yüksek osmotik basınç farklılığı nedeniyle sınırlı bir kullanım alanına sahiptirler [4]. Bununla birlikte ters ozmoz ünitelerinin hem ilk yatırım maliyetleri hem de işletme giderleri yüksektir. $\mathrm{Bu}$ uygulamanın diğer dezavantajları; arıtma sonucu oluşan konsantre akımın atıksu kaynağındaki neredeyse tüm kirleticileri içermesi, oluşan konsantre akımın ilave olarak arıtma gerektirmesi ve toplam çıkış suyunun yaklaşık olarak \% 20'lik bir kısmının arıtılamaması, arıtılıış akımın geri dönüşüm için oldukça yüksek miktarda kirletici içermesi olarak sıralanabilir [2]. Nanofiltrasyon uygulamaları kullanılarak haşıllama işleminde kullanılan kimyasalların geri kazanılması da mümkün olabilmektedir. Arıtılan atıksu hacminin yaklaşı olarak \% 10'u kadar konsantre akım oluşabilmektedir. Benzer şekilde oluşan konsantre akım atıksu içerisinde bulunan organik ve inorganik kirleticilerin bir kısmını içermekle beraber, bu akımın farklı yöntemlerle arıtılması gerekmektedir. Ultrafiltrasyon ve mikrofiltrasyon işlemleri ise tekstil endüstrisinden kaynaklanan atıksuların arıtımında yaklaşık 0,02 mm'lik partikül boyutundaki yüksek bağıl moleküler kütleye sahip organik maddelerin ve askıda katı maddelerin miktarlarının azaltılması için kullanılmaktadır. Ultrafiltrasyon ve mikrofiltrasyon tekniklerinin inorganik tuz konsantrasyonu üzerinde önemli bir etkisi bulunmamaktadır ve atıksuyun içerdiği boyar maddeler başka bir materyal üzerine adsorplanarak giderilemediği sürece renk giderimi sağlamamaktadır. Diğer bir ifadeyle bu iki teknik tek başına uygulandığında sadece KOİ ve AKM giderimi açısından olumlu sonuçlar alınabilmektedir. Diğer bir yöntem olan elektrodiyaliz yönteminde ise hem atıksuyun içerdiği boyaların giderilmesi sağlanır hem de kullanılan elektrolitlerin yeniden kullanılmak üzere geri kazanımı mümkün olabilmektedir [2].

\subsection{Kimyasal Yöntemler}

Boyaların kimyasal maddelerle parçalandığı oksidasyon prosesleri kolay uygulanması sebebiyle genellikle en çok kullanılan metottur [9]. Ayrıca bu prosesler daha az kimyasal kullanımını gerektirir ve daha kısa bekleme sürelerine sahiptir [6]. Kimyasal oksidasyon prosesinin temel esası kimyasal türler arasında gerçekleşen elektron transferine dayanmaktadır. Bu proses indirgenme yükseltgenme prosesi olarak da adlandırılmaktadır. Kimyasal oksidasyonun amacı, kararsız ara ürüne veya son ürüne dönüştürülmek üzere su içerisinde bulunan bir maddenin kimyasal olarak oksitlenmesi olarak ifade edilebilir [1]. Kimyasal oksidasyonda boya moleküllerinin aromatik halkalarının kırılması sağlanır [8] ve böylece boyalar kısmen veya tamamen atıksulardan giderilir [6]. Kimyasal oksidasyon yöntemi ile renk gideriminde boyar maddelerin yapısında bulunan kromofor gruplarındaki konjuge bağ sistemleri parçalanır ve renk veremez hale gelir (kısmi oksidasyon). Böylece indirgenen ara ürünlerin biyolojik oksidasyon için uygun formlara dönüştürülmesi sağlanır. Neredeyse tüm boyalar birçok konjuge olmuş 
veya aromatik bağlar içerirler ve seçilen oksitleyici madde doymamış bağlarla reaksiyon vererek bileşiği daha küçük molekül yapısına sahip bileşiklere indirgemektedir [2]. Bu proseste genel olarak kullanılan oksitleyici maddeler ozon, fenton reaktifi ve peroksit olarak sıralanabilir [6].

Son yıllarda farklı endüstriyel atıksuların arıtımında ve tekstil endüstrisinde, etkili bir şekilde renk ve KOI giderimi sağlamak amacıyla Fenton reaktanı kullanılmaktadır [7]. Fenton reaksiyonları birçok organik bileşiği parçalama kabiliyeti sebebiyle yaygın olarak kabul görmektedir. Ayrıca çevrede hidroksil radikalleri aracıllığılla gerçekleşen oksidasyonlar için de önemli bir yol sağlamaktadır. Fenton reaksiyonu olarak bilinen reaksiyon iki değerlikli demirin hidroksil radikali meydana getirmek üzere hidrojen peroksit ile oksidasyonudur [4]. Hidroksil radikalleri oldukça güçlü oksitleyicilerdir ve boyaların çoğu ile güçlü bir şekilde reaksiyona girer. Ayrıca hidroksit radikalleri tekstil atıksuyundaki birçok organik ve inorganik kimyasalları oksitleme yeteneğine sahiptir [9]. Özellikle biyolojik arıtma kademesinde inhibisyona neden olan ya da toksik özelliklere sahip olan atıksuların oksidasyonu için Fenton reaktifi oldukça uygun bir yöntemdir [2]. Bu sistemlerin ilk yatırım maliyetleri düşüktür ve düşük hidrolik bekleme süresine sahiptirler [13]. KOİ, renk ve toksisite gideriminde sağladığı avantajların yanı sıra bazı dezavantajları da bulunmaktadır [2]. Fenton prosesinin kullanımında yatırım ve işletme maliyetleri ile enerji tüketimi çok düşüktür fakat kimyasal tüketimi oldukça yüksek seviyelerdedir [7]. Bununla birlikte korozyon oluşturma potansiyeline sahiptirler [13].

Tekstil endüstrilerinden kaynaklanan atıksulardaki azo boyar maddelerin ozonla etkili bir şekilde parçalandığı raporlanmıştır [12]. Tekstil endüstrisi atıksularının arıtılmasında ozon, genellikle organik maddeler giderildikten sonra atıksuyun suyun geri kazanılması amacıyla gerekli renk standardını sağlamak ve biyolojik arıtmadan önce yüksek moleküllü bileşiklerin oksitlenmek suretiyle biyolojik arıtma için uygun hale getirmek için kullanılmaktadır [2]. Ozonlama, renk giderimi ve degredasyonda mükemmel potansiyele sahip olması; insan sağlığına minimum zararlı etkisi, çamur oluşturmaması, artık ozonun kolayca su ve oksijene parçalanabilmesi; kolay üretilebilirliği açısından tercih edilir [11]. Ozon kullanımının sağladığı en önemli avantajların başında gaz formunda kullanıldığından dolayı atıksuyun hacmini artırmaması ve çamur oluşumunun önlenmesi gelmektedir [7, 9]. Bununla birlikte biyolojik olarak ayrışamayan maddelerle tepkimelere girmesi ozonun bir diğer önemli özelliğidir. Ozonla kimyasal oksidasyon, tekstil endüstrisi atıksularında KOİ gideriminden çok renk giderimi ve biyolojik ayrışabilirliği artırmak amacıyla kullanılmaktadır [1]. Ozon, dispers boyalar ile suda çözünmeyen boyaların dışındaki boyalardan kaynaklanan rengin gideriminde de oldukça etkilidir. Reaktif boyalarla kıyaslandığında kükürtlü, disperse, küp ve pigment boyaların çok daha yavaş bir şekilde ozonla tepkimeye girdiği bildirilmiştir [7]. İçerisinde reaktif boyaların bulunduğu atıksuların ozonla arıtılması işleminde atık suyun toplam organik karbon konsantrasyonunda belirgin bir düşüş yaratmadığı raporlanmıştır [1]. Ozon, çok kuvvetli tekstil atıksularının direkt arıtılması için yeterli olmadığı için, ozonun son arıtma işlemi olması ya da kimyasal koagülasyonu takiben uygulanması önerilmektedir [7]. İlave olarak reaksiyona giremediği organik maddeler de bulunmaktadır [1].

Renk içeren atıksuların klorlu birleşiklerle oksitlenmesini sağlamak kullanılan arıtma yöntemleri arasındadır. Bu yöntemde klor iyonları boya moleküllerinin amino gruplarına etki ederek azo bağlarının kırılmasını sağlar. Klor konsantrasyonundaki artışa paralel olarak renk giderimi de artar. Renk gideriminin sağlanmasında sodyum hipoklorit kullanımı asit ve direkt boyalar için tatmin edici sonuçlar 
vermektedir. Reaktif boyaların arıtımı için ise daha uzun zamana ihtiyaç vardır. Son yıllarda alıcı ortamlarda meydana getirdiği olumsuz etkilerinden dolayı atıksulardan boyar maddelerin gideriminde klor kullanımı azalmıştır [3].

\subsection{Biyolojik Yöntemler}

Biyolojik arıtma prosesleri tekstil atıksularının arıtımında sıklıkla kullanılmaktadır [17]. Sentetik boaların biyolojik proseslerle giderimi ucuzdur, işletme maliyetleri düşüktür ve tam mineralizasyon sonucunda oluşan ürünler toksik değildir [12]. Biyolojik proseslerin sağladığı diğer avantaj daha az çamur oluşturmasıdır [9]. Biyolojik prosesler genellikle KOI ve askıda katı maddelerin gideriminde etkili olsa da atıksulardan renk gideriminde büyük ölçüde yetersiz kalmaktadırlar [17]. Çünkü geleneksel aktif çamur sistemleri ile tekstil endüstrisinde kullanılan birçok boya bileşikleri ya biyolojik olarak çok zor indirgenebilmekte ya da hiç bozunmamaktadır [11]. Bu sebeple tekstil atıksuyu ile evsel atıksu karıştırılarak arıtılsa bile konvansiyonel aktif çamur sistemlerinde etkili bir renk giderimine ulaşılamamaktadır [7]. Atıksuda bulunan bazik, direk ve bazı azo boyar maddeler mikroorganizmalar tarafından biyolojik olarak indirgenememekle birlikte bir kısmı adsorbe edilerek ortamdan uzaklaştırılabilmektedir [11]. Diğer bir ifadeyle biyosorpsiyon (aktif çamur yüzeyinde tutunma) ile renk giderimi mümkün olmaktadır [2]. Azo boyar maddelerin mikrobiyal parçalanmaya karşı dirençli olmasının nedeni, boyar maddenin ürün üzerindeki kalıcılığı sağlamak amacıyla renklerin solmamasını sağlayacak şekilde üretilmelerinden kaynaklanmaktadır [4]. Azo boyar maddelerin biyolojik arıtımında döner biyolojik diskler kullanılır, burada azo boyar maddeler bakteriler tarafindan asimile edilir [12].

Biyosorpsiyonu etkileyen en önemli faktörler çamurun kalitesi, suyun sertliği, temas süresi ve substrat konsantrasyonu olarak sıralanabilir [2,11]. Ön çöktürme işleminin uygulanması, çözünmeyen dispers ve vat boyaların arıtma verimi büyük ölçüde artırmakla birlikte aktif çamurda adsorpsiyona dayalı olarak bazik ve direkt boyaların orta halde arıtılması sağlanabilmektedir. Oldukça yaygın bir biçimde kullanılan reaktif ve asit boyalar ise çok az arıtılmaktadır [1]. Aktif çamur sistemlerinde karşılaşılan problemlerden biri de Nocardia köpüklenmesi ve filamentli bakterilerden kaynaklanan kabarma olayıdır. Bu olayın kompleks yapısı tam olarak anlaşılmamakla beraber yüksek konsantrasyonda nişasta ve yüzey maddelerinin bu duruma sebep olabileceği düşünülmektedir [7]. Biyolojik arıtma ile renk giderimi aktif çamur sistemlerinde havalandırma havuzlarına toz aktif karbon ilave edilerek geliştirilebilmektedir. Toz karbon kullanımının sağladığı diğer avantajlar BOI ve KOI gideriminde verimi artırması ve köpük probleminin oluşumunu önlemesi olarak sıralanabilir [11]. Bu proses adsorpsiyon kadar verimli renk giderimi sağlamaktadır ve ilave olarak \% $20-55$ arasında bir renk giderimi elde edilebilir [2].

Anaerobik arıtma, renk, organik halojenler ve ağır metallerin gideriminde olumlu sonuçlar vermektedir. Atıksuyun yüksek bir renk konsantrasyonuna sahip olması durumunda anaerobik arıtmayı takiben, aktif çamur sistemine beslenerek \% 90'ın üzerinde KOI ve renk giderimine ulaşllabilmektedir. İçerisinde yağ ve deterjanlar gibi organikleri bulunduran yün yıkama atıksularında biyolojik olarak zor ayrışabilen organik maddeler de yüksek oranda giderilebilmektedir [7]. Boyar maddelerin anaerobik parçalanması, özellikle aerobik şartlar altında parçalanamayan boyaların gideriminde etkili olmaktadır. Anaerobik şartlarda Azo boyaların büyük bir kısmı biyolojik olarak kolay ayrışan aromatik aminlere dönüşürler [11]. Fakat anaerobik olarak renk gideriminin sağlanabilmesi için ilave karbon kaynağına 
ihtiyaç duyulmaktadır. İlave karbonun metan ve karbondioksit gazına dönüşmesi neticesinde elektronlar açığa çıkar. Reaktif boyalar açığa çıkan bu elektronların son elektron alıcısı olarak rol oynar ve böylece azo bağının indirgenmesi sağlanır. Bu işlem oksijenin varlığında gerçekleşmediği için aerobik prosesten önce anaerobik şartlarda azo bağının kırılması sağlanmalıdır [4]. Anaerobik arıtmanın ürünlerinden olan toksik - kanserojen aromatik aminlerin oluşması anaerobik arıtmanın dezavantajlarından bir tanesidir [2].

\subsection{Elektrokimyasal Yöntemler}

Elektroliz yönteminde, asit boyaların demir hidroksit oluşumu ile etkili bir şekilde giderilmesi gerçekleştirilmektedir [1]. Laboratuar ölçekli çalışmalarda \%80 renk giderimi sağlanmıştır. Konvansiyonel yöntemlere nazaran, koagülasyon, elektroliz ve aktif çamur sistemlerinin toplamı daha ucuz ve daha etkili KOİ giderimine sahiptir [7, 15].

Fotokataliz yönteminde ise UV ışılları, $\mathrm{H}_{2} \mathrm{O}_{2}$ ve $\mathrm{TiO}_{2}$ heterojen katalizörlerin birlikte kullanımı ile boya çözeltilerinde renk giderimi sağlanır [7]. Bu sistemde tam renk giderimi sağlanamamakla birlikte toplam olarak $\% 90$ karbon giderimi elde edilebilmektedir [14]. $\mathrm{UV} / \mathrm{H}_{2} \mathrm{O}_{2}$ prosesi ise oldukça yavaş, maliyetli ve tam ölçekli uygulamalarda $\mathrm{UV} / \mathrm{TiO}_{2}$ prosesine göre daha az etkilidir. Buna bağlı olarak kısa reaksiyon sürelerinde etkili bir KOİ giderimine ulaşlırken çamur ve tuz oluşumu da olmamaktadır. UV geçirimliliğinin belli boya çözeltilerinde sınırlı olmasından dolayı ozondan sonra son arıtım basamağı olarak UV teknolojisinin kullanımı daha iyi sonuçlar vermektedir [7]. Biyolojik olarak arıtılmış çıkış suyuna uygulanan fotokalitik oksidasyon prosesleri ile ilave olarak \% 97 KOİ giderimine ulaşılmaktadır. $\mathrm{UV} / \mathrm{H}_{2} \mathrm{O}_{2}$ prosesi için yatırım maliyeti ve işletme maliyetleri yüksek olmasının yanında kimyasal tüketimi çok düşük olsa da enerji tüketimi çok yüksektir [1].

Atıksulardan boya gideriminde kullanılan diğer bir proses ise elektrokoagülasyon prosesidir. Elektrokoagülasyon atıksu içerisinde genellikle demir ya da aliminyumdan yapılan çözünebilir anotların elektriksel olarak çözünmesi ile metal hidroksitlerin oluşturulduğu bir prosestir. Helişmiş ülkelerde bu yöntem endüstriyel atıksuların arıtımında sıklıkla kullanılmaktadır [16].

\section{Sonuçlar}

- Tekstil atıksularının içeriği ve karakterizasyonu işletmelerin üretim yöntemlerine göre değiş̧iklik göstermektedir ve kirletici parametreler oldukça geniş bir aralıkta değişmektedir.Bu yüzden, arıtımında kullanılacak yöntemler belirlenmeden önce atıksuyun kompozisyonu tespit edilerek proses seçiminin yapılması önemli bir husustur.

- Tekstil atıksularının arıtımında yaygın olarak kullanılan yöntemler, bu yöntemlerin uygulama alanları, sundukları avantajlar ve dezavantajlar Tablo 1'de sunulmuştur.

- Genel bir açıdan bakıldığında sınırlı bir kirletici konsantrasyonuna sahip tekstil atıksularının arıtımında Fenton prosesler renk ve KOİ giderimi sağlamada başarıyla kullanılabilmektedir.

- Yüksek derişimlerde kirletici içeren tekstil atıksularının arıtımında ise membran proseslerin kullanılması daha fazla avantaj sağlayabilmektedir ve bu proseslerle \%95 oranına varan renk giderimi sağlamak mümkün olmaktadır. Sonuç olarak tekstil atıksularının arıtımında membran prosesler gelecek için büyük bir potansiyel sunmaktadır ve daha geniş bir uygulama alanı bulacağı söylenebilir. 
Nevşehir Bilim ve Teknoloji Dergisi Cilt 6(ICOCEE 2017 Özel Sayı) 388-396 2017

Tablo 1. Tekstil atıklarının arıtılması için çeşitli teknolojilerin değerlendirilmesi [7, 15]

\begin{tabular}{|c|c|c|c|}
\hline Proses & Uygulama Alanı & Performans & Dezavantajları \\
\hline Fenton oksidasyonu & Ön arıtma & $\begin{array}{l}\text { Tam renk giderimi, düşük } \\
\text { maliyet ve işletme maliyeti }\end{array}$ & $\begin{array}{c}\text { Asidik pH } \\
\text { Çamur oluşumu }\end{array}$ \\
\hline Elektroliz & Ön arıtma & Tam renk giderimi, ucuz & Köpüklenme \\
\hline Filtrasyon & Ana veya son aritma & $\begin{array}{l}\text { Yüksek performans, su ve tuz } \\
\text { geri kazanımı }\end{array}$ & $\begin{array}{l}\text { Konsantre akımın ele } \\
\text { alınması ve bertarafi }\end{array}$ \\
\hline Biyolojik Ayrışma/Aktif Çamur & Ana aritma & KOİ, N giderimi & $\begin{array}{l}\text { Yüksek artan KOİ, N, } \\
\text { renk ve deterjan }\end{array}$ \\
\hline Koagülasyon/Flokülasyon & Ön, ana ve son aritma & $\begin{array}{l}\text { Tam renk giderimi, suyun geri } \\
\text { kullanımı }\end{array}$ & $\begin{array}{l}\text { Her zaman etkili değil, } \\
\text { çamur bertarafı }\end{array}$ \\
\hline Ozonlama & Son aritma & $\begin{array}{l}\text { Tam renk giderimi, suyun geri } \\
\text { kullanımı }\end{array}$ & Pahalı, aldehit oluşumu \\
\hline Adsorpsiyon & Ön ve son aritma & $\begin{array}{l}\text { Yeni adsorbentler etkili ve ucuz, } \\
\text { suyun geri kullanımı }\end{array}$ & $\begin{array}{l}\text { Yüksek bertaraf veya } \\
\text { rejenerasyon maliyeti }\end{array}$ \\
\hline Fotokataliz & Son aritma & Renk ve toksik giderimi & Sadece son arıtma amaçlı \\
\hline
\end{tabular}

\section{Kaynaklar}

[1] Dörtkol M., "Doğal ve Modifiye Kil ile Sulu Çözeltilerden Boyar Madde Giderimi” Nevşehir Hacı Bektaş Veli Üniversitesi, Fen Bilimleri Enstitüsü, Yüksek lisans tezi, 86s, Nevşehir, 2014

[2] Şahin, Y., "Asit Boya Banyosu Atıksularının Kimyasal Prosesler İle Ön Arttılabilirliğinin İncelenmesi" İstanbul Teknik Üniversitesi, Fen Bilimleri Enstitüsü, Yüksek lisans tezi, 137s, İstanbul, 2006

[3] Kocaer, F.O., Alkan, U., "Boyar Madde İçeren Tekstil Atıksularının Arıtım Alternatifleri" Uludağ Üniversitesi Mühendislik-Mimarlk Fakültesi Dergisi, 1(7), 47-55, 2002

[4] Midık, F., "Reaktif Sarı 145 Azo Boyar Maddesinin Ve 2,4-Diklorofenoksiasetik Asit Pestisitinin Yüksüz Nano Demir, Fenton Ve Foto-Fenton Prosesleri İle Karşılaştırmalı Giderilmesi” Çukurova Üniversitesi, Fen Bilimleri Enstitüsü, Yüksek lisans tezi, 89s, Adana, 2011

[5] Joshi, M., Bansal, R., Purwar, R., "Colour removal from textile effluents" Indian Journal of Fibre \& Textile Research, 29, 239-259, 2004

[6] Gupta, V.K., Suhas, "Application of low-cost adsorbents for dye removal - A review" Journal of Environmental Management, 90, 2313-2342, 2009

[7] Baburşah, S., "Tekstil Endüstrisi Atıksularının Gerikazanımı ve Yeniden Kullanılması" İstanbul Teknik Üniversitesi, Fen Bilimleri Enstitüsü, Yüksek lisans tezi, 117s, İstanbul, 2004

[8] Robinson, T., McMullan, G., Marchant, R., Nigam, P.,, "Remediation of dyes in textile effluent: a critical review on current treatment technologies with a proposed alternative" Bioresource Technology, 77, 247-255, 2001

[9] Holkar, C.R., Jadhav, A.J., Pinjari, D.V., Mahamuni, N.M., Pandit, A.M., "A critical review on textile wastewater treatments: Possible approaches" Journal of Environmental Management, 182, 351-366, 2016

[10] Verma, A.K., Dash, R.R., Bhunia, P., "A review on chemical coagulation/flocculation technologies for removal of colour from textile wastewaters" Journal of Environmental Management, 93, 154-168, 2012 
[11] Bahadır, E.B., "Tekstil Endüstrisi Arıtılmış Atıksularında Renk ve Öncelikli Kirleticilerin Ozon Teknolojisi İle Gideriminin Araştırılması” Namık Kemal Üniversitesi, Fen Bilimleri Enstitüsü, Yüksek lisans tezi, 140s, Tekirdağ, 2012

[12] Forgacs, E., Cserhati, T., Oros, G., "Removal of synthetic dyes from wastewaters: a review" Environment International, 30, 953-971, 2004

[13] Arıc1, Y., “Tekstil Endüstrisinde Reaktif Boyarmaddelerden Kaynaklanan Rengin Fenton Prosesi ile Giderilmesi” İstanbul Teknik Üniversitesi, Fen Bilimleri Enstitüsü, Yüksek lisans tezi, 88, İstanbul, 2000

[14] Erol, E., "Pamuklu Tekstil Endüstrisi Atıksularının Arıtımı” Kocaeli Üniversitesi, Fen Bilimleri Enstitüsü, Yüksek lisans tezi, 82, Kocaeli, 2007

[15] Bianchi, R., Verstraete, W., Vandevivere, P.C., "Treatment and reuse of wastewater from the textile wet-processing industry; Review of emerging Technologies" J. Chem. Technol. Biotechnol., 72, 289-302, 1998

[16] Raghu, S., Basha, C.A., "Chemical or electrochemical techniques, followed by ion exchange, for recycle of textile dye wastewater" Journal of Hazardous Materials, 149, 324-330, 2007

[17] Bidhendi, G.R.N., Torabian, A., Ehsani, H., Razmkhah, N., "Evaluation of Industrial Dyeing Wastewater Treatment With Coagulants and Polyelectrolyte As a Coagulant Aid", Iran. J. Environ. Health. Sci. Eng., 1(4), 29-36, 2007. 